\title{
Discovering genes are made of DNA
}

Maclyn McCarty

The Rockefeller University, 1230 York Avenue, New York 10021, USA (e-mail: mccartm@rockefeller.edu)

Maclyn McCarty is the sole surviving member of the team that made the remarkable discovery that DNA is the material of inheritance. This preceded by a decade the discovery of the structure of DNA itself. Here he shares his personal perspective of those times and the impact of the double helix.

Editor's note - For a long time, biologists thought that 'genes', the units of inheritance, were made up of protein. In 1944, in what was arguably the defining moment for nucleic acid research, Oswald Avery, Maclyn McCarty and Colin MacLeod, at Rockefeller Institute (now University) Hospital, New York, proved that DNA was the material of inheritance, the so-called stuff of life. They showed that the heritable property of virulence from one infectious strain of pneumococcus (the bacterial agent of pneumonia) could be transferred to a noninfectious bacterium with pure DNA ${ }^{1}$. They further supported their conclusions by showing that this 'transforming' activity could be destroyed by the DNA-digesting enzyme DNAase $e^{2,3}$.

This work first linked genetic information with DNA and provided the historical platform of modern genetics. Their discovery was greeted initially with scepticism, however, in part because many scientists believed that DNA was too simple a molecule to be the genetic material. And the fact that McCarty, Avery and MacLeod were not awarded the Nobel prize is an oversight that, to this day, still puzzles.

"The pivotal

discovery of

20th-century biology."

Joshua Lederberg, Rockefeller

University, 1994, referring to the discovery by McCarty, Avery and MacLeod.

Maclyn McCarty at The Rockefeller University.

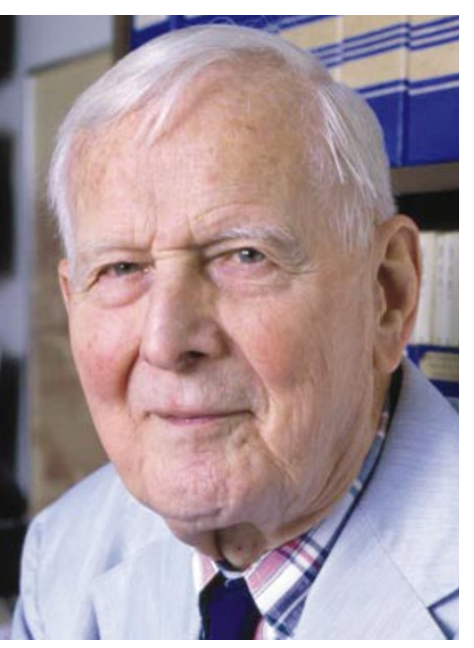

wall could be transferred by the DNA preparations, indicating that the purified DNA also contained other genes of the bacterium.

Our findings continued to receive little acceptance for a variety of reasons, the most significant being that the work on the composition of DNA, dating back to its first identification 75 years earlier, had concluded that DNA was too limited in diversity to carry genetic information. Even those biologists who had considered the possibility had dropped the idea, and the prevailing dogma was that if genes are composed of a known substance, it must be protein.

There were a few biologists who took a different view, the most notable being Erwin Chargaff, who changed his area of research to DNA after reading our 1944 paper $^{1}$. His work revealed the great diversity in DNA isolated from various sources, and that despite this diversity the amount of adenine always equalled that of thymine, and the amount of guanine that of cytosine. The latter finding was an important factor in the next significant advance in the field - the Watson-Crick determination of the double helical structure of DNA.

After the change in my research activity, I continued to give talks on our work on pneumococcal transformation and found the acceptance of the probable genetic role of DNA still to be minimal. However, I was convinced that it was only a matter of time before our results would become established.

Even though I was no longer involved in research on the subject, I continued to follow the developments as they appeared in the literature. Thus, when the papers of Watson and Crick describing the double helical structure of DNA were published in Nature in 1953 , I certainly grasped the significance of their findings and was pleased to see such illuminating results come from a structural approach. I was not so pleased, however, that they failed to cite our work as one reason for pursuing the structure of DNA.

The concept of the double helix also hastened the silencing of those who had clung to the idea of genes as proteins. As a progressively larger body of investigators joined the study of the genetic role of DNA, there was an expanding amount of new information, starting with the resolution of the genetic code. By the end of the twentieth century, subsequent work on the mechanisms by which DNA is replicated with each cell division, is reshuffled with each generation, and is repaired when mistakes arise - the importance of which can in each case be traced back to the finding that DNA is the hereditary material - has transformed research in all areas of biology, technology and medicine.

doi:10.1038/nature01398

1. Avery, O. T., MacLeod, C. M. \& McCarty, M. Studies of the chemical nature of the substance inducing transformation of pneumococcal types. Induction of transformation by a desoxyribonucleic acid fraction isolated from Pneumococcus Type III. J. Exp. Med. 79, 137-158 (1944).

2. McCarty, M. Purification and properties of desoxyribonuclease isolated from beef pancreas. J. Gen. Physiol. 29, 123-139 (1946).

3. McCarty, M. \& Avery, O. T. Studies of the chemical nature of the substance inducing transformation of pneumococcal types II. Effect of desoxyribonuclease on the biological activity of the transforming substance. J. Exp. Med. 83, 89-96 (1946). 